\title{
Zagrajmy w powieść. Recenzja książki Tomasza Majkowskiego Języki gropowieści. Studia o różnojęzyczności gier cyfrowych
}

\author{
Marcin Fisz \\ Uniwersytet Szczeciński \\ m.fisz@02.pl | ORCID 0000-0003-3800-1976
}

DoI: $10.14746 / \mathrm{hl} .2020 .13 .14$ | received: 16.11 .2020 | accepted: 14.12 .2020

Obecnie gry cyfrowe stanowią samoistne, wysoce dochodowe medium cyberkultury, cieszące się zainteresowaniem polskich naukowców z różnych dziedzin: nauk społecznych, humanistycznych, ścisłych (Surdyk, 2009, s. 227-228), a szczególnie literaturoznawców - po wielkim sukcesie gry Wiedźmin 3: Dziki Gon, inspirowanej opowiadaniami i powieściami Andrzeja Sapkowskiego ${ }^{1}$. Przekłada się to na aktualnie trwające prace nad grami, których inspiratorzy korzystają z twórczości Stanisława Lema (Grygiel, 2019) czy Jacka Piekary (Biedrzycki, 2019). Takie śmiałe poczynania pokazują, jak ważne jest kontynuowanie badań nad cyfrową

1 Wiedźmin 3: Dziki Gon do dziś jest określany mianem najlepszej gry, jaka kiedykolwiek powstała. Zdobył ponad 800 nagród, co przełożyło się także na wielki sukces finansowy studia CD Projekt Red (Kieszek, 2019; Mucharzewski, 2016). 
rozrywką, aby zgłębiać jej fenomen. Celowo nazywam te przedsięwzięcia śmiałymi, gdyż tylko nieliczne, sfinalizowane projekty wirtualnej zabawy osadzone $\mathrm{w}$ świecie pierwotnie wykreowanym przez fantazje pisarzy odniosły zdecydowany sukces.

Chciałbym podkreślić, iż wokół polskiego oglądu literaturoznawczego napisano kilka istotniejszych rozpraw ${ }^{2}$ - przykładem służą Piotra Kubińskiego Poetyka gier wideo. Cechy swoiste (2014), Michała Dawida Żmudy Gry cyfrowe jako palimpsesty tradycji literackiej (2018), Marty Tymińskiej Awatar $w$ użyciu. Problematyka rozumienia pojęcia $w$ literaturze przedmiotu i środowisku osób grających (2019), Julii Czerniuk Jak przeczytać grę i zagrać $w$ literaturę? Kategoria gry w kontekście różnych teorii: literatury, kultury i mediów (2019). Do tej grupy zalicza się też książka Tomasza Majkowskiego ${ }^{3}$ Języki gropowieści (2019), której poświęcony jest niniejszy tekst.

Majkowski koncentruje się na specyficznym gatunku gier cyfrowych, który określa mianem gropowieści. Wokół tej kategorii opisuje wybrane elementy starannie dobranych gier, wykorzystując koncepcje Michaiła Bachtina, zorientowane na wielogłosowość, różnojęzyczność oraz dialogowość. Gropowieść jako gatunek gier cyfrowych ukazuje kwestie tworzące wieloaspektowy portret świata, w którym w głównej pozycji znajduje się zorganizowane działanie i wykonawca czynności, czyli gracz. Tytułowe zróżnicowanie językowe obejmuje fabułę, a także prawa rządzące rozgrywką. Gropowieści „posługują się zespołami motywów, praktyk i wyobrażeń charakterystycznych dla starszych od nich form kulturowych, które służą do nadawania sensu przedstawianemu w grze działaniu, lecz pozostają w dialogicznym napięciu" (Majkowski, 2019, s. 64). Ponadto badacz w swojej publikacji przedstawia genealogię omawianej kategorii gier, jej rozwój, a także zbiór określających ją cech.

Autor książki nie zamierza przekonywać czytelnika, że gry są odmianą literatury, aczkolwiek zauważa ich pewne punkty styczne. Twierdzi,

2 Wskazuję tutaj rozprawy, które zostały napisane w związku z procedurami zdobywania stopnia lub tytułu naukowego.

3 Tomasz Z. Majkowski - groznawca, bada literaturę i kulturę popularną. Adiunkt w Katedrze Antropologii Literatury i Badań Kulturowych Wydziału Polonistyki Uniwersytetu Jagiellońskiego. Kierownik w Ośrodku Badań Groznawczych. Uzyskał habilitację na podstawie recenzowanej w tym artykule książki pt. Języki gropowieści. Studia o różnojęzyczności gier cyfrowych. 
iż gropowieść to tak znaczący gatunek gier jak analogicznie dla piśmiennictwa istotna jest powieść. Stąd wynika przesunięcie ludologicznego akcentu z kulturowej tradycji zabawy na sposób przekazywania treści. Gracz, świadomie lub nie, uczestniczy w fabule. Czy grę można jednak do pewnego stopnia „czytać”, interpretować niczym medium literackie, korzystając z aparatu literaturoznawczego?

W książce wymienione zostają niedoskonałości przekładu pewnych aspektów z obszaru teoretycznoliterackiego na grunt groznawczy. Słowo zaczyna zatracać istotność na rzecz obrazu, co wytwarza kolejne problemy, ale pewne kwestie rozgrywają się podobnie - przekonuje Majkowski. Sądzę, że klucz do pełnego ujęcia stanowi w tym względzie interdyscyplinarność. Pozwala ona badać gry z różnych punktów widzenia w ich możliwej „totalności". Trudno orzec, czy właściwe jest zamykanie groznawstwa tylko pod jedną kategorią badawczą, czysto ludologiczną, której zwolennicy chcieliby objąć w jednej nauce profesjonalną analizę gier. Dziś wiemy, że ustanowić ludologię jako pełnoprawną dziedzinę trudno ze względów formalnych, ale także z powodu wielu pytań o status gier cyfrowych (Surdyk, 2009).

Stworzenie aparatu badawczego poprzez odwołanie się do teorii Bachtinowskich, moim zdaniem, umacnia groznawstwo na polu literaturoznawczym. Jednakże czy nauki Bachtina, który żył przed erą zaawansowanych gier cyfrowych, a dodatkowo odwoływał się do całkiem innego medium, czyli powieści literackiej, naprawdę są pomocne? Wiele spostrzeżeń rosyjskiego literaturoznawcy i filozofa rzeczywiście można odnieść do nowych mediów. Ponadto gry cyfrowe nie mają jeszcze swoistego, autonomicznego języka opisu. Ludolodzy ciągle pracują nad czymś, co pokuszę się nazwać interdyscyplinarną fuzją - niewykluczone, iż dopiero ona wyłoni swego rodzaju ramy takiego języka. Wykorzystanie koncepcji dotyczących powieści literackiej na gruncie badań groznawczych jest więc uzasadnione.

Twórcy gier wideo chcą zbudować wirtualne uniwersum, w którym rozgrywa się jakaś historia bohatera lub wielu bohaterów. Aby taki świat był wiarygodny dla gracza, inicjatorzy muszą dopasować sposób wypowiedzi NPC ${ }^{4}$, ich wygląd, gesty, mimikę, sposób poruszania się itd. Istotną

4 NPC (ang. Non-Player Character) - wirtualna postać niekontrolowana przez gracza. O charakterze takiej postaci decyduje gatunek gry lub fabuła. 
różnicą pomiędzy literaturą a grą cyfrową jest oddziaływanie na wiele zmysłów, co tworzy immersję - zanurzenie w nierzeczywisty świat (Maj, 2015; Kłosiński, 2018). Autor Języków gropowieści często nawiązuje do tego aspektu w swoich analizach. Gra cyfrowa oddziałuje na wzrok, słuch, dotyk (ponieważ poruszamy kontrolerem, sterując daną postacią). Obraz stanowi dominantę nadaną przez twórców. Mający przywilej wyboru gracz może realizować dany etap wirtualnej przygody na różne sposoby; jest dodatkowym głosem w opowiastce, decydującym o jej kształcie w zależności od gatunku ${ }^{5}$, dlatego interpretacja nieraz przybiera różne kształty. Rozważania na temat immersji są znaczące także w kontekście etyki. Nie od dziś za źródło agresji, choćby wśród młodzieży, obwinia się gry cyfrowe (Matusiak, 2015). Zabrakło mi ujęcia tego wątku w książce, zwłaszcza podczas analiz konkretnych gropowieści dotyczących brutalności czy cielesności. Chodzi mi tutaj o niebezpieczeństwa, jakie może nieść za sobą zbyt mocne zanurzenie w cyfrowy świat.

Kilka wątków omawianej pozycji szczególnie mnie zaciekawiło. Podkreślę, że w książce skupiono się na dwóch fundamentalnych elementach gropowieści - dialogiczności i różnojęzyczności, w których analizie główną inspiracją jest monografia Bachtina z 1935 roku Słowo w powieści. Aby przedstawić te dwa aspekty, Majkowski wykorzystał wewnętrzne niezgodności cyfrowego artefaktu ${ }^{6}$ - językowe dysonanse mające znaczenie dla samej realizacji gropowieści - podzielając przy tym ogólnie przyjętą tezę, że gry są narzędziem komunikacji z graczem. Badacz twierdzi, iż omawiany przez niego tytułowy gatunek gier wideo korzysta z aspektów audialnego, wizualnego, haptycznego i kilku innych jednocześnie, co eksponuje ujęcie totalne cyfrowego uniwersum gry oraz gracza, realizującego w nim swoją wolę.

Na podstawie epizodu z Uncharted 3 unaoczniona zostaje wielojęzyczność świata przedstawionego. Majkowski wskazuje tutaj ideowe języki w duchu Bachtina: charakter opowieści o losach bohatera, sposób realizowania rozgrywki, szacowanie zysków i strat, przekonując, że przenikają się one i często wchodzą w konflikt, czyli wcześniej wspomniany

5 Odwołuję się tutaj przede wszystkim do gier cRPG, w których decyzje gracza wpływają na rozgrywkę, a niekiedy na wirtualną przestrzeń czy zachowanie postaci niegrywalnych.

6 Sformułowanie „cyfrowy artefakt” traktuję jako synonim „gry cyfrowej”. 
dysonans. Dzieje się to poprzez fakt, że język gry z jednej strony wymusza pośpiech w opisywanej scenie, z drugiej zaś nakłania do ostrożności i strategii. Są to swoistego rodzaju sensy nadawane przez wirtualną rzeczywistość, pewne idee rozumiane tak, jak Bachtin odnosił się do „języka karnawału” w Problemach poetyki Dostojewskiego, ujęte w grupę wizualnych aspektów, przenośni i wyrazów ekspresji.

Majkowski, przyjmując słownik teoretyczny Bachtina, przechodzi do kwestii teorii powieści literackiej i jej zróżnicowania względem gropowieści: ,języki literatury występują w układzie linearnym, w gropowieści natomiast egzystują symultanicznie" (Majkowski, 2019, s. 121). Po dłuższym wywodzie na temat bachtinowskiego rozumowania autor książki buduje obraz różnojęzyczności powieściowej, czyli „jednoczesną obecność w tekście różnych, społecznie ukorzenionych systemów wypowiadania się, niejednokrotnie odnoszących się w rozmaity sposób do tego samego przedmiotu i pozostających w dialogowym napięciu" (tamże, s. 122). Ta kwestia służy za klucz do analizy gropowieści pod kątem różnojęzyczności, tyczy się zatem aspektów obrazu, muzyki, części tekstowych itp. ujętych na poziomach estetyczno-fabularnym oraz regulacyjno-sprawczym. Ten pierwszy obejmuje profilowanie uniwersum, zapełnianie go postaciami oraz nadawanie treści w stosunku do przedstawianej historii. Drugi określa sposób wykonywania wyznaczonych w grze misji, a także możliwości gracza.

Różne gry cyfrowe posługują się analogicznymi sposobami wyrazu. Lara Croft i Nathan Drake jako protagoniści słynnych serii gier przygodowych podobnie walczą z bandytami, uciekają z rozmaitych niebezpiecznych sytuacji itd. Język przygody stanowi główny obszar dialogu, a niektóre elementy konwencji zmieniają ich tor. Dostrzeżona analogia dotyczy dwugłosowości. W powieści literackiej treść wypowiadana przez bohatera to jednocześnie słowo autora. Gra cyfrowa realizuje wolę gracza wyrażaną za pomocą kontrolera i przekładającą się na czynności wirtualnego awatara.

Kwestie polemiczne dotyczące moralności gier cyfrowych pozostają dla Majkowskiego nierozstrzygnięte, jednakże autor książki postanawia w rozdziale piątym odnieść się do tej problematyki pod kątem gatunku gropowieści. Analiza jest skoncentrowana na obrazie destrukcji powiązanej z jednoczesnym odczuwaniem satysfakcji przez gracza. Skupiono się tutaj również na metodach ukazywania brutalności i cielesności, co 
twórcy gier często przedstawiają groteskowo. Ponadto prawa fizyki oraz inteligencja NPC powinny być, na swój sposób, wiarygodne na tyle, na ile to tylko możliwe. Majkowski słusznie zauważa rozdźwięk pomiędzy realistycznym przedstawieniem np. ran odniesionych podczas strzelaniny, w której brał udział bohater wirtualnego uniwersum, a przejściem segmentu gry dającego zabawę. Awatar może otrzymać niezwykle dotkliwe obrażenia i wrócić piorunująco szybko do wspaniałej kondycji, jeśli przez sześć sekund schował się za jakąś osłoną.

Cielesność bohaterów czy wrogów z gier wideo zazwyczaj jest mocno fetyszyzowana - główni protagoniści są wzorami męskiego czy damskiego ciała; mężczyźni to wysportowani, przystojni atleci, a kobiety wizerunkiem przypominają modelki jak z żurnali. Wrogowie bywają przedstawiani z silną tendencją do przerośniętych kształtów, wulgarnego wyrazu twarzy itp. Badacz tłumaczy, że takie elementy przekładają się w gropowieściach dwuwymiarowo: na estetykę ludzką i nieludzką. Przy tej pierwszej Majkowski skupia się na deformacjach ludzkiego ciała, druga zaś dąży do odwzorowania realizmu świata przedstawionego. Ta kwestia znajduje uzasadnienie u rosyjskiego uczonego, którego filozofia cały czas stanowi najważniejszą inspirację. Bachtin podobną dwoistość opisuje w pracy Twórczości Franciszka Rabelais'ego, gdzie nazywa ów aspekt realizmem groteskowym. Istotny sposób funkcjonowania tego typu realizmu zostaje omówiony przez Majkowskiego na podstawie wizerunku Lary Croft z serii gier Tomb Raider. Skupiono się tutaj na relacji obrazu protagonistki nie wobec uwarunkowań społecznych dotyczących płci, lecz wobec konwencji przygodowej.

Podobnie jak Lara Croft stanowi żeński odpowiednik Indiany Jonesa, tak też charakter narracyjny gry był wzorowany na filmach przygodowych Stevena Spielberga. Protagonistka wyrusza na wyprawy do obcych krain, aby odnajdować cenne artefakty, skarby. Tomb Raider jest następcą pierwszych gier zręcznościowych: gracz w ciele Lary skacze z platformy na platformę, unika przeciwników, eliminuje ich za pomocą broni białej lub palnej, a elementy powieściowe przedstawiane są w obrębie przerywników filmowych. Rzecz dzieje się w trójwymiarowym uniwersum dzięki wykorzystaniu najnowszych (w tamtych czasach) technologii.

Główna bohaterka została zaprezentowana w Tomb Raider jako supersprawna fizycznie, niezwykle inteligentna, entuzjastycznie nastawiona 
do niebezpiecznych przygód młoda kobieta. Ubrana jest w obcisły strój, podkreślający pośladki i bardzo duży biust. Często nie waha się użyć przemocy, aby zrealizować swój cel. Konwencja gry ukazuje tę postać jako pozytywną, która broni się przed niebezpieczeństwem ze strony ludzi czy dzikich zwierząt tylko w ostateczności, co wcale nie rozwiązuje szeroko debatowanego przez specjalistów zagadnienia moralnego. Majkowski zauważa, iż model tego typu postaci żeńskich przedstawianych jako heroiny był w latach 90. xx wieku, czyli w okresie powstania pierwszej gry z serii Tomb Raider, powszechny, wzorowany na osobistościach pokroju Xeny (bohaterka serialu Xena - wojownicza księżniczka) czy Buffy (protagonistka serialu Buffy - postrach wampirów). Mimo wyraźnych związków z kinem przekład języka przygodowego na grunt gier cyfrowych nie jest najważniejszy. Tomb Raider udaje swoje pierwotne źródła, co zapewniają możliwości technologiczne zaprogramowanej gry oraz liczba osiągalnych przez gracza wyborów. Badaczowi nie chodzi tutaj o szyderstwo, lecz o wskazywanie i wyczulanie na reguły rządzące opowiadaniem przygody.

Autor Języków gropowieści wykorzystuje idee Bachtina dotyczące aspektów związanych z sonetami Don Kichota. Rosyjski uczony tłumaczy:

parodystyczny sonet nie należy do gatunku sonetu. Forma sonetu w sonecie parodystycznym nie jest wcale gatunkiem, czyli formą całości, jest natomiast przedmiotem przedstawienia; sonet jest tutaj bohaterem parodii (cyt. za: tamże, s. 165).

Majkowski podkreśla przy tym: „w wypadku gropowieści parodystyczność nie polega na powtarzaniu wyłącznie cech formalnych kina; dokonuje się w przekładzie na inne sposoby obrazowania" (tamże). W grze Tomb Raider zwielokrotnione zostają niebezpieczeństwa, przeszkody, zagadki. Przerywników filmowych pojawia się znacznie mniej niż elementów rozgrywki. Wirtualne uniwersum ogranicza się do sekwencji korytarzy, które prowadzą do końca zadania wyznaczonego przez fabułę. Charakterystyczny jest brak kontaktu protagonistki z dziką kulturą, która, jak akcentuje naukowiec, stanowi zbyteczną część, aczkolwiek okazuje się ważnym punktem wielu filmów czy powieści literackich o tematyce przygodowej. Zatem bohaterka sterowana przez gracza nie będzie ratować egzotycznych mieszkańców danej krainy itp. Wszystkie elementy wirtualnego świata, takie jak ludzie czy zwierzęta, są zazwyczaj przeszkodą do przezwyciężenia. Zatem wewnętrzna parodystyczność 
działa na poziomie narracyjno-estetycznym gropowieści i jest wyolbrzymiana przez zasady i mechanikę rozgrywki. Sama Lara Croft stanowi parodię postaci kobiecych występujących w powieściach przygodowych ogromne wargi, szerokie biodra, nieproporcjonalnie wąska talia. Dodam od siebie, że graczom podoba się ta groteskowość. Wskazuje na to niezwykła popularność serii Tomb Raider.

W rozdziale siódmym Majkowski proponuje analizę gier tzw. sandboksowych - Sleeping Dogs i Saints Row: The Third pod kątem destrukcji dziejącej się na tradycyjnym poziomie estetyczno-fabularnym. Chodzi tutaj o karnawałową swobodę i stosunek do pozorowanej przemocy opisanej przez Bachtina w Twórczości Franciszka Rabelais'ego. Gry wideo możemy w istocie zakwalifikować do karnawałowych środków wypowiedzi, a także do obszernej kultury śmiechu.

Produkcje wybrane do analizy osadzone są w konwencji gangsterskiej. Otwarte uniwersum ma przypominać prawdziwy świat - wielkie miasto. Podczas rozgrywki przedzieramy się przez rzesze nieprzyjaciół innych gangsterów lub policję, a zależne jest to od fabuły i bohaterów. Warstwa estetyczno-fabularna i mechanika gry przecinają się, tworząc groteskowe wyolbrzymienie polegające na tym, że ,jeżeli, załóżmy, podstawowy mechanizm gry to walka z nieprzyjaciółmi, częstotliwość walk i liczba wrogów, których gracz wyprawia na tamten świat, przyprawiłaby o wstydliwy rumieniec najbardziej nawet krwawe kino" (tamże, s. 179). Mamy zatem wirtualne miejsce, w którym gracz odczytuje konkretne i wymowne zasady tworzące porządek.

Autor Języków gropowieści zauważa ciekawe elementy karnawału destrukcji, zlokalizowanego $\mathrm{w}$ obydwu grach na poziomie estetyki i fabuły. Po podobnej sekwencji wydarzeń jak ta wspomniana przed chwilą bohater „ukrywa swoją tożsamość, zostaje zdemaskowany, konfrontuje się z przedstawicielem władzy i wskutek tej konfrontacji zostaje wrzucony w karnawałowy świat na opak, którym rządzą antagoniści, a on sam znajduje się na dole drabiny społecznej" (tamże, s.191). Gracz, kierując poczynaniami protagonisty, musi odwrócić ten stan rzeczy, aby wrócić do tego, co było na początku. Zatem mamy tutaj ideologię karnawałową - bohater trafia do świata na opak, a przez spiętrzenie się różnych zdarzeń dochodzi do tzw. detronizacji karnawałowej wynikającej z fabuły gropowieści: 
dotychczasowy zwierzchnik przestępczej społeczności zostaje brutalnie wyeliminowany, rytualnie poćwiartowany, a następnie zastąpiony groteskową wersją samego siebie, postacią fizycznie zdeformowaną (tamże).

Na uwagę zasługuje rozdział ósmy. Przeprowadzana jest tutaj wnikliwa analiza gry Assassin's Creed iı pod kątem wątków transgresyjnych, wykorzystujących mechanizm satyry menippejskiej. Jest to metoda narracyjna sięgająca po skandale i paradoksy, „by poddać próbie ideę filozoficzną" (tamże, s. 197).

Assassin's Creed II stanowi gropowieść osadzoną w dwóch światach futurystycznym i historycznym. Główny bohater, Desmond Miles, ma w kodzie genetycznym cząstki genów swojego przodka, należącego niegdyś do bractwa zabójców, tzw. asasynów, od wieków prowadzących wojnę z templariuszami. Dzięki temu może przenosić się - za pomocą swoistego wehikułu - do czasów, w jakich żył jego praojciec. Protagonista ma na celu zrekonstruować pamięć ascendenta, aby odnaleźć pradawny skarb ukryty gdzieś we współczesności, w której żyje Miles. Gracz kontroluje bohatera, gdy ten przenosi się do np. dawnej Florencji czy Wenecji w ciele Ezia - przodka Desmonda, by tam dokonywać postępów fabularnych najczęściej poprzez zabójstwa kolejnych NPC i wydobywanie z nich różnorakich informacji. Wojna pomiędzy asasynami a templariuszami stanowi klasyczną wersję walki dobra ze złem. Templariusze chcą utworzyć system kontroli nad światem - asasyni bronią wolności ludzi.

Gropowieść Assassin's Creed II przekracza według Majkowskiego granice swojego gatunku i podważa założenia ideologiczne gry cyfrowej osadzonej w otwartym świecie. Twórcy nie robią tego wprost, wykorzystują subtelne środki przekazu. Kwestie moralne związane z zabijaniem ludzi w Assassin's Creed II są usprawiedliwiane najpierw przez zemstę, ponieważ młody Ezio Auditore doświadcza brutalnego zabójstwa swojej rodziny. Dalej odbieranie życia tłumaczone jest przez ideologię bractwa asasynów, którzy przecież walczą o większą, słuszną sprawę, co wymaga to ofiar - w szczególności mordowania złych templariuszy. Mimo wszystko Ezio zawsze okazuje wybranym ofiarom należyty szacunek, dając im wypowiedzieć ostatnie zdania i zamykając im oczy ze słowami: „Requiescat in pace”. Taka sekwencja dzieje się jakby w innym świecie - na chwilę czas zostaje zatrzymany. Autor książki zauważa tutaj podobieństwo do satyr menippejskich, „gdzie bohaterowie ustawicznie wykłócają się u drzwi, by wpuszczono ich do 
środka: niekiedy, jak w przypadku Udynienia Boskiego Klaudiusza Seneki są to [...] drzwi wiodące w zaświaty" (tamże, s. 212).

Treść ostatniej rozmowy w życiu złoczyńcy ma paradoksalny wymiar. Zabójca jest kapłanem, który rozgrzesza człowieka przed śmiercią, a trzymając na rękach swoją ofiarę, uruchamia skojarzenie $\mathrm{z}$ „Marią rozpaczającą nad martwym ciałem Chrystusa” (tamże). Tego typu scena służy temu, by dowieść, że protagonista ukazany został jako narzędzie ostatecznej sprawiedliwości. Ponadto:

Finalna konwersacja parodiuje przyjętą w popkulturze manierę prezentacji ostatnich słów konającego: nie dochodzi do pojednań, sekrety nie zostają wyjawione, ostatnie mądrości to komunały (tamże, s. 212-213).

Kiedy agonia przeciwnika się kończy, czas zostaje przywrócony, zatem Ezio znowu musi walczyć np. ze strażnikami w miejscu, gdzie musiał zamordować znaczącą postać. Asasyni zabijają w imię wolności wszystkich ludzi, lecz tak naprawdę interesują ich tylko konkretne osoby, pociągające za sznurki organizacji templariuszy. Sądzę, że ta analiza jest trafna. Przeciętny gracz raczej nie skupia się tak dokładnie na wątkach uśmiercania nic nieznaczących, wirtualnych przeciwników. Głębsze przemyślenia prowadzą do wniosku, że jedni i drudzy są siebie warci - dobro i zło to kwestie subiektywne.

Warto podkreślić wybór gier do wielowątkowych analiz funkcjonowania gatunku gropowieści, czyli m.in. Assassin's Creed II, Uncharted 3, Saint's Row: The Third, Sleeping Dogs, Tomb Raider, Wiedźmin 3: Dziki Gon. To bardzo znane produkcje, stanowiące istotny element cyberkultury. W tym świetle Majkowski stara się spojrzeć na fenomen cyfrowych artefaktów - z segmentu masowego, wysokobudżetowego.

Inspiracja filozofią Michaiła Bachtina owocuje ciekawym omówieniem tytułowego gatunku gropowieści. Sądzę, że jest to pozycja wyrażająca złożoność warstw ideologicznych, którymi posługują się gry wideo, aby nie tylko dostarczyć wirtualnej zabawy, ale także uczyć o cyfrowej rzeczywistości, wkradającej się coraz bardziej do naszego współczesnego świata. Zastanawiające, czy przedstawione aspekty naukowe, wyrażone w humanistycznej refleksji, nie wymkną się jednak spod dotąd stosowanych, klasycznych aparatów badawczych, choćby literaturoznawczych jak w Słowie w powieści Bachtina. Nasuwa się pytanie: co tracimy, wykorzystując ten kierunek w groznawstwie, a co zyskujemy? 


\section{Literatura}

Biedrzycki, P. (12 września 2019). The Dust odsłania karty. Budżet gry „I, the Inquisitor" na podstawie powieści Jacka Piekary wyniesie 14,5 $\mathrm{mln} \mathrm{zł}$. Online: <http://strefainwestorow.pl/artykuly/gaming/20190912/the-dust-cykl-inkwizytorski>. Data dostępu: 29 maja 2020.

Grygiel, B. (30 maja 2019). Powstanie gra na podstawie prozy Lema! Nareszcie! Online: <http://www.focus.pl/artykul/nareszcie-powstanie-gra-na-podstawie-prozy-lema-190530041711>. Data dostępu: 29 maja 2020.

Kieszek, N. (19 maja 2019). Mijają 4 lata od premiery Wiedźmina 3 - gry, której dużo zawdzięczają akcjonariusze CD PROJEKT, producenci gier i cały rynek kapitałowy. Online: <http://strefainwestorow.pl/artykuly/ gaming/20190519/wiedzmin-3-cd-projekt>. Data dostępu: 29 maja 2020.

Kłosiński, M. (2018). Hermeneutyka gier wideo. Interpretacja, immersja, utopia. Warszawa: Instytut Badań Literackich PAN - Wydawnictwo.

Maj, K. (2015). Czas światoodczucia. Imersja jako nowa poetyka odbioru. Teksty Drugie, 26(3), 368-394.

Majkowski, T. (2019). Języki gropowieści. Studia o różnojęzyczności gier cyfrowych. Kraków: Wydawnictwo Uniwersytetu Jagiellońskiego.

Matusiak, R. (2015). Gry jako źródło zachowań niepożądanych wśród młodzieży. Warmińsko-Mazurski Kwartalnik Naukowy. Nauki Społeczne, 4(4), 99-109.

Mucharzewski, M. (20 marca 2016). „Wiedźmin 3” najczęściej nagradzana gra $w$ historii. Online: <http://gazetalubuska.pl/wiedzmin-3-najczesciej-nagradzana-gra-w-historii/ar/9762897>. Data dostępu: 16 listopada 2020.

Surdyk, A. (2009). Status naukowy ludologii. Przyczynek do dyskusji. Homo Ludens, 1(1), 223-243. Online: <http://www.ptbg.org.pl/wp-content/uploads/2020/05/Augustyn-SURDYK-Status-naukowy-ludologii.-Przyczynek-do-dyskusji.pdf>. Data dostępu: 9 grudnia 2020. 
